\title{
The Acceptance of Tax Office Automation System (VEDOP) By Employees: Factorial Validation of Turkish Adapted Technology Acceptance Model (TAM)
}

\author{
Ahmet Ferda Çakmak (Corresponding author) \\ Zonguldak Karaelmas University, Faculty of Economics and Administrative Sciences \\ Department of Business Administration, Zonguldak, Turkey \\ E-mail: ahmet.cakmak@karaelmas.edu.tr \\ Serkan Benk \\ Zonguldak Karaelmas University, Faculty of Economics and Administrative Sciences \\ Department of Public Finance, Zonguldak, Turkey \\ E-mail: serkan.benk@karaelmas.edu.tr \\ Tamer Budak \\ Zonguldak Karaelmas University, Faculty of Economics and Administrative Sciences \\ Department of Public Finance, Zonguldak, Turkey \\ E-mail: tamer.budak@karaelmas.edu.tr
}

Received: June 6, 2011

doi:10.5539/ijef.v3n6p107
Accepted: July 5, 2011

Published: November 1, 2011

URL: http://dx.doi.org/10.5539/ijef.v3n6p107

\begin{abstract}
In this study, Davis's (1989) The Technology Acceptance Model (TAM) is used as a theoretical framework to extend and complement extant tax officials by acceptance of technological components of Tax Office Automation System (VEDOP) in Turkey. Relying on the basic TAM model, we examine the extent to which perceived usefulness (PU), perceived ease of use (PE), and attitudes (AT) toward VEDOP affect behavior intentions (BI). The data set of the study was obtained from the survey applied to 185 individual tax officials in the city of Zonguldak. Consistent with the hypotheses, the results in general provided that the core constructs of TAM namely PU, PE and AT are positively and significantly determine BI of automation system used by tax officials. As predicted, these three factors explained a large proportion of variance in Behavioral Intention to use the VEDOP system. Internet and VEDOP training experience have not found to effect significantly.
\end{abstract}

Keywords: Technology Acceptance Model, Theory of reasoned action, Tax Office Automation System (VEDOP), Turkey

\section{Introduction: Turkish Tax Office Automation System (VEDOP)}

In today's knowledge based world, providing public services are heavily depend on information and communication technologies. The internet has simply become the basic information communication and sharing area of the future. While information technologies provide austerity at an important level, they also improve the quality of the public service. One of the important application area related to the use of information technologies in the public services is taxation. Especially among the members of OECD, electronic tax return, payment systems and tax automation systems generated in this area gain an increasing importance. Electronic tax management applications firstly started in the USA, and then spread in other developed and developing countries. Factors such as information and communication technologies which develop rapidly together with the process of globalization, gain strength and decrease costs and the increasing information sharing have extended the electronic tax management applications all over the world. 
Turkey has also been included in this global trend; Tax Office Automation Project (VEDOP), and correspondingly e-government applications and taxation services have started to be implemented through using computer technology on a large scale.

Turkish tax system involves a variety of different tax types that have different time periods of collection. What is required from a typical business is to prepare more than 30 tax returns and declaration forms annually and visit tax offices to submit tax returns nearly three times per month. As well as wasting the taxpayers' time, this paper-based system could also be considered an inefficient use of the tax officials. For these reasons tax office automation projects pursue three goals: (a) ensuring a more equitable distribution of the tax burden (tax equity), (b) making tax collections more efficient (reduce administrative costs of taxation) and (c) providing better services to citizens and businesses (reduce compliance costs of taxation) (OECD, 2007).

As is seen in Figure 1, Tax Office Automation Project (VEDOP) started as a pilot project in 1995. The first phase, which includes the period from 1998 to 2001, had a budget of USD 75 million. The second phase of the VEDOP project began in 2004 with a budget of USD 64 million. The responsible agency is Turkey's Revenue Administration (RA), which is a semi-autonomous agency within the body of the Ministry of Finance with 44000 personnel and 599 tax offices (GIB, 2011).

The project aims to develop (OECD, 2007);

A network: Allow high-speed communication between all tax offices.

E-Filing: Receive all tax returns electronically.

Improved service: Increase the quality of service to taxpayers.

E-tax collection: Promote electronic tax revenue collection (through banks).

Data warehouse: Generate information to improve tax policies and audit strategies, and detect non-declared taxes.

Taxpayer call centre: Answer questions and assist taxpayers.

Internet tax office: Online tax office.

The new systems support integration and data exchanges with other public and private institutions (ex: public and private banks, courts, land offices etc.) that use Extensible Markup Language (XML); facilitate interoperability between tax offices; and provide more uniform services for taxpayers across the country.

The project enables taxpayers to submit declarations electronically for several different types of taxes including income tax and corporate tax, value-added tax, special consumption tax, stamp tax and banking transaction tax. The declarations could be submitted by taxpayers directly, or by means of a financial consultant who will be required to file electronically. The goal is to make electronic filing of tax returns obligatory for businesses in the future - as soon as all tax offices have been connected to the network and digital signatures have been implemented (OECD, 2007).

The primary objective of this research is to predict and explain VEDOP technology acceptance and usage behavior. Tax officials have to use the VEDOP system to perform their job functions; therefore a volitional choice on actual usage is not an option for employees. However, an unaccepted change in the organization may negatively affect employee's job satisfaction, feelings toward their supervisors, and loyalty toward the organization (Brown et.al, 2002). Also, sabotage and unfaithful appropriation of technology, and the resulting costs to organizations associated with such behavior appears to be another potential risk that should be prevented. Therefore, in this study the processes underlying in the technological change acceptance are intended to be revealed. Within this context the Technology Acceptance Model (TAM) is reviewed. Based on this review, a research model is suggested and described. Details of the statistical analysis of the proposed model are presented, followed by a discussion of the results. Finally, implications and limitations of the study are discussed.

\section{Technology Acceptance Model}

Technology Acceptance Model (TAM) was developed from Theory of Reasoned Action (TRA) by Davis (Davis, 1989). The Theory of Reasoned Action (Ajzen and Fishbein, 1980) assumes that beliefs influence attitude and social norms which shape a behavioral intention guiding or even dictating an individual's behavior consecutively. Intention is the conceptual representation of a person's willingness to perform a given behavior, and it is considered to be the immediate antecedent of behavior.

As is seen in Figure 2, TRA has two core constructs of intention: (a) attitude toward behavior and (b) subjective norm associated with that behavior. The attitude toward the behavior is the previous attitude of a person toward performing that behavior. It suggests that people think about their decisions and the possible outcomes of their 
actions before making any decision that is meant to be involved or not involved in a given behavior. This theory views the intention of an individual whether to perform a given behavior or not as the immediate determinant of an action, and attitude is determined by the person's beliefs and evaluation of behavioral outcomes. So an individual, who strongly believes that positive outcomes will be caused by the performance of a particular behavior, will have positive attitudes towards that behavior. In contrast, if a person strongly believes that a particular behavior will have a negative outcome, then there will be negative attitudes towards that behavior.

Subjective norm (SN) is the social pressure exposed to the person or the decision maker to perform the behavior. SN states an individual's perception about the thoughts of other people concerning his or her behavior in question (Leach, et al., 1994). What other individuals or groups will think, agree or disagree about the decision of a person to perform a given behavior and how important these other individuals or groups play a vital role for the decision maker. So it is normal that sometimes people will consult others before making any decisions.

TRA is a broadand well-researched intention model that has been implemented extensively for the purpose of predicting and explaining behavior across many domains and virtually any human behavior (Ajzen and Fishbein, 1980). This theory is often used by the information system researchers to study the determinants of IT (information technology) innovation usage behavior (Han, 2003). Although current models of technology acceptance have their roots in many diverse theoretical perspectives, much literature related to technology acceptance begins studies with the TRA.

Technology Acceptance Model used TRA as a theoretical basis for the purpose of specifying the causal linkages between two key beliefs: perceived usefulness (PU) and perceived ease of use (PE) and users' attitudes (AT), intentions (BI) and actual computer usage behavior. Behavioral intention is jointly determined by attitude and perceived usefulness. Attitude is determined by perceived usefulness and perceived ease of use (see Figure 3). TAM replaces determinants of attitude of TRA by perceived ease of use and perceived usefulness. Perceived usefulness is also influenced by perceived ease of use because if other things are equal, the system (technology) could be more useful as long as it is easier (Venkatesh and Davis, 2000).

Generally, since TAM specifies general determinants of individual technology acceptance, it can be and has been applied to explain or predict individual behaviors across a broad range of end user computing technologies and user groups (Davis et al., 1989).

The aim of TAM is to provide a clarification of the determinants of computer acceptance that is in general capable of explaining user behavior across a broad range of end-user computing technologies and user populations, while at the same time being both parsimonious and theoretically justified. But because it incorporates findings accumulated from over a decade of IS research, it may be especially appropriate for modeling computer acceptance (Davis et al., 1989).

\section{Research Model and Hypotheses}

Figure 4 shows the research model to be empirically tested in this study. This model wasconstructed to answer the research questions raised earlier and is derived from the theoriesdescribed in the previous section.

A series of testable hypotheses can be developed from the proposed research model, as shownbelow:

$\boldsymbol{H}_{1}$ : Tax official's perceived usefulness of VEDOP will be significantly influenced by his or her perceived ease of use of VEDOP.

$\boldsymbol{H}_{2}$ :Tax official's attitude of VEDOP will be significantly influenced by his or her perceived ease of use of VEDOP.

$\boldsymbol{H}_{3}$ :Tax official's attitude of VEDOP will be significantly influenced by his or her perceived usefulness of VEDOP.

$\boldsymbol{H}_{4}$ : Tax official's behavioral intention of VEDOP will be significantly influenced by his or her perceived usefulness of VEDOP.

$\boldsymbol{H}_{5}$ : Tax official's attitude of VEDOP will be significantly influenced by his or her behavioral intention of VEDOP.

\section{Data Analysis and Results}

\subsection{Participants}

Participants were 185 tax officer enrolled at Zonguldak district of Presidency of Tax Administration in Turkey. The total number accounted for $68 \%$ of the number $(\mathrm{n}=350)$ who have been approached to participate in this study. Demographic attributes of the respondents are shown at Table 1 .

\subsection{Measures}

A survey questionnaire was administered to the participants (tax officials) who volunteered for this study. The instrument was composed of 17 statements on PU (adapted from Davis, 1989), PE (adapted from Davis, 1989), AT 
(adapted from Cheng et al., 2006), and BI (adapted from Gu et al., 2009). Participants gave their opinions to each statement on a 7-point Likert scale, ranging from 1 (strongly disagree) to 7 (strongly agree).

Participants from various tax offices completed the survey questionnaire provided by the researchers. All participants were briefed on the purpose of this study and their rights not to participate in the study. On average, each participant took not more than 10 min to complete the questionnaire.

\subsection{Data analysis}

The statistical analysis comprised two stages. The first stage examined the descriptive statistics of the measurement items and assessed the reliability and validity of the measure used in this study. The second stage tested the proposed research models and this involved assessing the contributions and significance of the manifest variables path coefficients.

\subsubsection{Descriptive statistics}

The descriptive statistics of the measurement items are shown in Table 2. All means were over 4, ranging from 4.57 to 5.92. In addition, $12(70 \%)$ out of 17 items in the measure have means 5.00 and above. This indicates an overall positive response to the constructs that are measured in this study. The standard deviations ranged from 1.307 to 1.698 , indicating a narrow spread of item scores around the mean.

\subsubsection{Convergent validity}

In the research model, both convergent and discriminant validity were assessed. Fornell and Larcker (1981) proposed three procedures to assess for convergent validity of the measurement items: (1) item reliability of each measure, (2) composite reliability of each construct, and (3) the average variance extracted. The item reliability of an item was assessed by its factor loading onto the underlying construct. Hair et al. (2006) suggested that an item is significant if its factor loading is greater than 0.50. As shown in Table 3, the eigenvalues of all constructs exceed 1.00 and the per cent of cumulative variance explained of these five constructs was $70.99 \%$. The factor loadings of all the items in the measure ranged from 0.86 to 0.53 (in bold). This exceeds the threshold set by Hair et al. (2006) and demonstrates convergent validity at the item level.

The internal consistency was assessed by means of the Cronbach alpha coefficient of each construct.The reliabilities of all the constructs are between 0.83 and 0.93 so the results presented in Table 2 attested to the high internal consistency of the instrument in which all values were above the suggested 0.70 level for scale robustness (Nunnally and Bernstein, 1994).The internal consistency of the measurement model was also assessed by computing composite reliability. As presented in Table 2, all constructs have a higher composite reliability than the benchmark of 0.70 recommended by Fornell and Larcker (1981). These indicators suggest that a high internal reliability for the data exists.

The final indicator of convergent validity, average variance extracted, is a more conservative test of convergent validity (Fornell and Larcker, 1981). It measures the amount of variance captured by the construct in relation to the amount of variance attributable to measurement error. Convergent validity is judged to be adequate when average variance extracted equals or exceeds 0.50 (i.e. when the variance captured by the construct exceeds the variance due to measurement error). As shown in Table 2, the convergent validity for the proposed constructs of the research model is adequate.

\subsubsection{Discriminant validity}

Discriminant validity exists when the variance shared between a construct and any other construct in the model is less than the variance that constructs shares with its indicators (Fornell et al., 1982).

Discriminant validity was evaluated by comparing the square root of the average variance extracted for a given construct, with the correlations between that construct and all other constructs. If the square roots of the AVEs are greater than the off-diagonal elements in the corresponding rows and columns exceed the correlations between a given construct and others in the model, this suggests that a construct is more strongly correlated with its indicators than with the other constructs in the model (Teo et.al, 2008). In Table 4, the diagonal elements in the correlation matrix have been replaced by the square roots of the average variance extracted. Discriminant validity appears to be satisfactory at the construct level in the case of all constructs.

\subsubsection{Test of the proposed model}

The research model in this study was tested using the structural equation model approach, using the computer software program LISREL 8.51 . This technique is chosen for its ability to examine a series of dependence relationships simultaneously, especially where there are direct and indirect effects among the constructs within the model (Hair et al., 2006). Bollen (1989) recommended a minimum sample size of 100 while Anderson and Gerbing 
(1988) recommended 200. A recent proposal by Hair et al. (2006) indicated that any study with five or fewer constructs, each with more than three items, and high item communality with 0.60 and higher, can adequately be estimated with sample size of 150 . In this study, the sample size is 185 and this was considered adequate on the basis of recommendation from research.

From the literature, it is a common practice to use a variety of indices to measure model fit in studies that use SEM as a technique for analysis (Kline, 2005). These are absolute fit indices that measure how well the proposed model reproduces the observed data. In other words, the fit indices evaluate the overall discrepancy between the implied and observed covariance matrices. The indices used in this study are the Goodness of Fit Index, Normed Fit Index, Standardized Root Mean Residual, and the Comparative Fit Index. Table 5 shows the level of acceptable fit and the fit indices for the proposed research model in this study. Results of the model test revealed an acceptable fit, all values satisfied the recommended level of acceptable fit (Hu and Bentler, 1999).

Figure 5shows the resulting path coefficients of the proposed research model. All five hypotheses were supported by the data. The results show that PU significantly influenced PE $(\beta=0.44, \mathrm{P}<0.001)$, supporting hypothesis H1. PE was also found to be significant in influencing AT $(\beta=0.72, \mathrm{P}<0.001)$, supporting hypotheses H2. PU was found to be significant in influencing $\mathrm{AT}(\beta=0.19, \mathrm{P}<0.001)$ and $\mathrm{BI}(\beta=0.57, \mathrm{P}<0.05)$, thus supporting hypotheses $\mathrm{H} 3$ and $\mathrm{H} 4$. AT was significant in influencing $\operatorname{BI}(\beta=0.55, \mathrm{P}<0.001)$, thus supporting hypotheses $\mathrm{H} 5$. A summary of the hypotheses testing results is shown in Table 6.

The test of the structural model test revealed the following results:

- Attitude towards use is a significant predictor of behavioral intention to use

- Perceived usefulness is a significant predictor of behavioral intention to use

- Perceived usefulness is a significant predictor of Attitudes

- Perceived ease of use is a significant predictor of Attitudes

- Perceived ease of use is a significant predictor of Perceived usefulness

\section{Conclusion}

This study is the first to assess adopted Tax Offices Automation system among tax officials in Turkish setting. It is very important to evaluate technology acceptance levels of users to enhance the chances of variety of new technology implementation and further implementation efforts. For the individual user of a specific information system, the results in general provided that the core constructs of TAM namely PU, PE and AT are positively and significantly determine BI of automation system used by tax officials. As predicted, these three factors explained a large proportion of variance in Behavioral Intention to use the VEDOP system. Internet and VEDOP training experience have not found to effect significantly.

Our study is subject to a number of limitations. One of the most important limitations of the study is the sample size of the survey. It is not quite possible to make inferences with about 185 responses on Turkish tax officials adoption of tax administration automation systems, yet still efforts to collect more data is underway.

Second, although in the literature review, theoretical background is discussed in a wider perspective including major behavioral based theories as well as their constructs, the analysis only involved to test and discuss the results of major TAM constructs namely PU, PE.

Finally, our sample size covers only one city (Zonguldak) in Turkey. Therefore, more researchers are called in a wide sample. Hence, this study is a currently work-in progress study that further analysis and interpretations of the results is still possible. This will be topic of the following studies.

\section{References}

Ajzen I, Fishbein, M. (1980). Understanding attitudes and predicting social behavior. Prentice Hall.

Anderson JC, Gerbing DW. (1988). Structural equation modelling: a review and recommended two-step approach. Psychological Bulletin. 103: 411-423, http://dx.doi.org/10.1037/0033-2909.103.3.411

Atuğ M. (2008). E-devlet kapsamında VEDOP uygulamaları ve karşılaşılan sorunlar, Ulusal e-devlet Konferansı. [Online] Available: http://www.edevletkonferansi.org/sunum/mehmet_atug.ppt (May 9, 2011)

Bollen KA. (1989). Structural Equations with Latent Variables. John Wiley \& Sons. New York.

Brown SA, Massey A, Montoya-Weiss MM \& Burkman JR. (2002). Do i really have to? User acceptance of mandated technology. European Journal of Information Systems. 11: 283-295, http://dx.doi.org/10.1057/palgrave.ejis.3000438 
Cheng TCE, Lam DYC \& Yeung, ACL. (2006). Adoption of internet banking: an empirical study in Hong Kong. Decision Support Systems. 42: 1558-1572, http://dx.doi.org/10.1016/j.dss.2006.01.002

Davis FD. (1989). Perceived usefulness, perceived ease of use and user acceptance of information technology. MIS Quarterly. 13 (3): 319-340, http://dx.doi.org/10.2307/249008

Davis FD, Bagozzi RP \& Warshaw PR. (1989). User acceptance of computer technology: a comparison of two theoretical models. Management Science. 35 (8): 982-1003, http://dx.doi.org/10.1287/mnsc.35.8.982

Fornell C \& Larcker DF. (1981). Evaluating structural equation models with unobservable variables and measurement error. Journal of Marketing Research. 48: 39-50, http://dx.doi.org/10.2307/3151312

Fornell C, Tellis GJ \& Zinkhan GM. (1982). Validity assessment: a structural equations approach using partial least squares. Proceedings. American Marketing Association Educators' Conference.

GİB (Gelir İdaresi Başkanlığı). (2011). 2011 Yılı Performans Programı. GİB Yayınları. Ankara.

Gu J, Lee S \& Suh Y. (2009). Determinants of behavioral intention to mobile banking. Expert Systems with Applications. 36 (9): 11605-11616., http://dx.doi.org/10.1016/j.eswa.2009.03.024

Hair JF, Black B, Babin B, Anderson RE \& Tatham RL. (2006). Multivariate Data Analysis.(6th ed.). Prentice Hall. Upper Saddle River. NJ.

Han S. (2003). Individual adoption of information systems in organisations: a literature review of technology acceptance model. TUCS Technical Report 540. TUCS, [Online] Available: http://iamsr.abo.fi/publications/openFile.php?pub_id=169(May 9, 2011)

Hu L, Bentler PM. (1999). Cutoff criteria for fit indexes in covariance structure analysis: Conventional criteria versus new alternatives. Structural Equation Modeling. 6: 1-55, http://dx.doi.org/10.1080/10705519909540118

Kline RB. (2005). Principles and practice of structural equation modeling. (2nd ed.). Guilford Press. New York.

Leach M, Hennessy M \& Fishbein M. (1994). Perception of easy-difficult: attitude or self-efficacy? Journal of Applied Social Psychology. 31(1): 1-20, http://dx.doi.org/10.1111/j.1559-1816.2001.tb02478.x

Nunnally JC, Bernstein IH. (1994). Psychometric theory. McGraw-Hill, Inc. New York.

OECD. (2007). OECD e-government studies Turkey. OECD Publications. Paris, http://dx.doi.org/10.1787/9789264028456-en

Teo T, Lee CB \& Chai CS. (2008). Understanding pre-service teachers' computer attitudes: applying and extending the technology acceptance model. Journal of Computer Assisted Learning. 24:128-143, http://dx.doi.org/10.1111/j.1365-2729.2007.00247.x

Venkatesh V \& Davis, FD. (1996). A model of the antecedents of perceived ease of use: development and test. Decision Sciences. 27 (3): 451-481, http://dx.doi.org/10.1111/j.1540-5915.1996.tb00860.x 
Table 1. Demographic attributes of the respondents

\begin{tabular}{|c|c|c|c|}
\hline & Frequency & Percent (\%) & Cumulative \\
\hline \multicolumn{4}{|l|}{ Gender } \\
\hline Male & 114 & 61.6 & 61.6 \\
\hline Female & 71 & 38.4 & 100.0 \\
\hline \multicolumn{4}{|l|}{ Age } \\
\hline Less than 30 & 1 & 0.5 & 0.5 \\
\hline $30-39$ & 49 & 26.5 & 27.0 \\
\hline $40-49$ & 99 & 53.5 & 80.5 \\
\hline Over 50 & 36 & 19.5 & 100.0 \\
\hline \multicolumn{4}{|l|}{ Education level } \\
\hline Junior high school & 3 & 1.6 & 1.6 \\
\hline High school & 30 & 16.2 & 17.8 \\
\hline Junior college & 34 & 18.4 & 36.2 \\
\hline College & 112 & 60.5 & 96.8 \\
\hline Graduate & 6 & 3.2 & 100.0 \\
\hline \multicolumn{4}{|l|}{ Tenure } \\
\hline Less than 10 & 9 & 4.9 & 4.9 \\
\hline $10-19$ & 56 & 30.2 & 35.1 \\
\hline $20-29$ & 104 & 56.2 & 91.4 \\
\hline Over 30 & 16 & 8.7 & 100.0 \\
\hline \multicolumn{4}{|c|}{ Participated in-service computer training } \\
\hline Yes & 115 & 62.2 & 62.2 \\
\hline No & 70 & 37.8 & 100.0 \\
\hline \multicolumn{4}{|c|}{ Participated in-service VEDOP training } \\
\hline Yes & 137 & 74.1 & 74.1 \\
\hline No & 48 & 25.9 & 100.0 \\
\hline
\end{tabular}

Table 2. Descriptive statistics and cronbach alphas $(\mathrm{n}=185)$

\begin{tabular}{|c|c|c|c|c|c|}
\hline & $\begin{array}{c}\text { Cronbach Alpha } \\
(>0.70)^{*}\end{array}$ & Composite Reliability $(>0.70)^{*}$ & $\operatorname{AVE}^{\mathrm{a}}(>0.50)^{*}$ & Mean & Std. Deviation \\
\hline Perceived Usefulness & 0.925 & 0.93 & 0.68 & & \\
\hline PU1 & & & & 5.23 & 1.662 \\
\hline PU2 & & & & 4.86 & 1.661 \\
\hline PU3 & & & & 5.22 & 1.525 \\
\hline PU4 & & & & 5.20 & 1.556 \\
\hline PU5 & & & & 5.36 & 1.523 \\
\hline PU6 & & & & 5.43 & 1.366 \\
\hline Perceived & 0.843 & 0.86 & 0.51 & & \\
\hline Ease of Use & & & & & \\
\hline PE1 & & & & 5.34 & 1.466 \\
\hline PE2 & & & & 5.81 & 1.307 \\
\hline PE3 & & & & 5.26 & 1.553 \\
\hline PE4 & & & & 4.94 & 1.451 \\
\hline PE5 & & & & 5.36 & 1.464 \\
\hline PE6 & & & & 5.38 & 1.488 \\
\hline Attitude & 0.826 & 0.83 & 0.71 & & \\
\hline AT1 & & & & 5.71 & 1.388 \\
\hline AT2 & & & & 5.92 & 1.435 \\
\hline Behavioral Intention & 0.853 & 0.86 & 0.68 & & \\
\hline BI1 & & & & 4.70 & 1.701 \\
\hline BI2 & & & & 4.57 & 1.690 \\
\hline $\mathrm{BI} 3$ & & & & 4.87 & 1.683 \\
\hline Overall & 0.934 & & & & \\
\hline
\end{tabular}

${ }^{*}$ Indicates an acceptable level of reliability or validity 
${ }^{a}$ AVE: Average Variance Extracted. This is computed by adding the squared standardized factor loadings divided by sum of squared standardized loading plus sum of indicator measurement error

PU, perceived usefulness; PE, perceived ease of use; AT, computer attitude; BI, behavior intention.

Table 3. Factor loadings of the measurement items

\begin{tabular}{|l|c|c|c|c|}
\hline & \multicolumn{4}{|c|}{ Component } \\
\hline & 1 & 2 & 3 & 4 \\
\hline PU1 & $\mathbf{. 6 9 1}$ & .348 & .236 & .110 \\
PU2 & $\mathbf{. 8 0 9}$ & .091 & .218 & .007 \\
PU3 & $\mathbf{. 8 2 6}$ & .218 & .188 & .160 \\
PU4 & $\mathbf{. 8 1 5}$ & .220 & .207 & .137 \\
PU5 & $\mathbf{. 7 8 2}$ & .321 & .199 & .179 \\
PU6 & $\mathbf{. 7 3 5}$ & .289 & .281 & .197 \\
PE1 & .310 & $\mathbf{. 6 4 8}$ & .057 & .240 \\
PE2 & .159 & $\mathbf{. 7 2 4}$ & -.010 & .252 \\
PE3 & .273 & $\mathbf{. 7 0 4}$ & .355 & -.097 \\
PE4 & .324 & $\mathbf{. 5 4 3}$ & .430 & .044 \\
PE5 & .147 & $\mathbf{. 7 0 4}$ & .230 & .228 \\
PE6 & .341 & $\mathbf{. 5 3 0}$ & .421 & .046 \\
BI1 & .342 & .236 &. $\mathbf{7 8 9}$ & .212 \\
BI2 & .335 & .175 & $\mathbf{. 8 0 9}$ & .141 \\
BI3 & .176 & .146 & $\mathbf{. 6 6 1}$ & .350 \\
AT1 & .098 & .159 & .273 & $\mathbf{. 8 5 7}$ \\
AT2 & .245 & .248 & .167 & $\mathbf{. 8 0 8}$ \\
\hline Eigenvalue & 8.356 & 1.517 & 1.193 & 1.002 \\
\hline \%Variance explained & 49.150 & 8.926 & 7.018 & 5.894 \\
\hline
\end{tabular}

Extraction Method: Principal Component Analysis.

Rotation Method: Varimax with Kaiser Normalization.

a Rotation converged in 6 iterations.

PU, perceived usefulness; PE, perceived ease of use; AT, computer attitude; BI, behavior intention.

Figures in bold represent loadings of the respective factors.

Table 4. Covariance matrix of latent variables

\begin{tabular}{lllll}
\hline & PU & PE & AT & BI \\
\hline PU & $(0.826)$ & & & \\
PE & 0.734 & $(0.715)$ & & \\
AT & 0.509 & 0.562 & $(0.842)$ & $(0.827)$ \\
BI & 0.680 & 0.698 & 0.552 & \\
\hline
\end{tabular}

Table 5. Fit indices of the proposed research model

\begin{tabular}{lll}
\hline Fit index & Level of acceptable fit & Proposed research model \\
\hline$\chi^{2}$ & $\chi^{2} /$ d.f. $<5$ & 1.60 \\
GFI & $>0.90$ & 0.900 \\
AGFI & $>0.85$ & 0.859 \\
NFI & $>0.90$ & 0.917 \\
NNFI & $>0.90$ & 0.957 \\
SRMR & $<0.10$ & 0.0446 \\
CFI & $>0.90$ & 0.966 \\
\hline
\end{tabular}

GFI, Goodness of Fit Index; NFI, Normed Fit Index; SRMR, Standardized Root Mean Residual; CFI, Comparative Fit Index; d.f., degrees of freedom. 
Table 6. Hypothesis testing results

\begin{tabular}{llll}
\hline Hypotheses & Path & Path coefficient & Results \\
\hline $\mathrm{H} 1$ & $\mathrm{PE} \rightarrow \mathrm{PU}$ & $0.44^{*}$ & Supported \\
$\mathrm{H} 2$ & $\mathrm{PE} \rightarrow \mathrm{AT}$ & $0.72^{*}$ & Supported \\
$\mathrm{H} 3$ & $\mathrm{PU} \rightarrow \mathrm{AT}$ & $0.19^{* *}$ & Supported \\
$\mathrm{H} 4$ & $\mathrm{PU} \rightarrow \mathrm{BI}$ & $0.57^{*}$ & Supported \\
$\mathrm{H} 5$ & $\mathrm{AT} \rightarrow \mathrm{BI}$ & $0.55^{*}$ & Supported \\
\hline${ }^{*} \mathrm{P}<0.001 ;{ }^{* *} \mathrm{P}<0.05$ & & &
\end{tabular}

PU, perceived usefulness; PE, perceived ease of use; AT, computer attitude; BI, behavior intention.

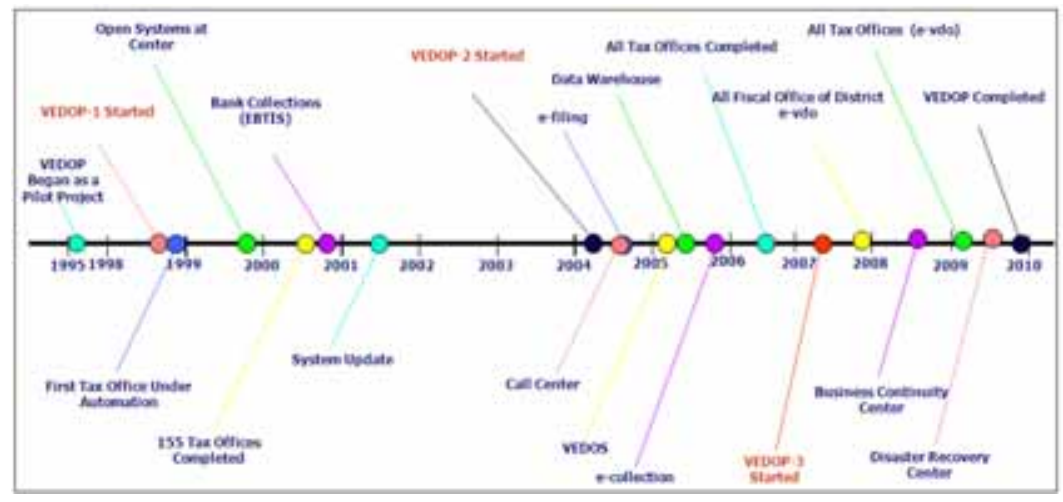

Figure 1. Historical development of VEDOP (Atuğ, 2008)

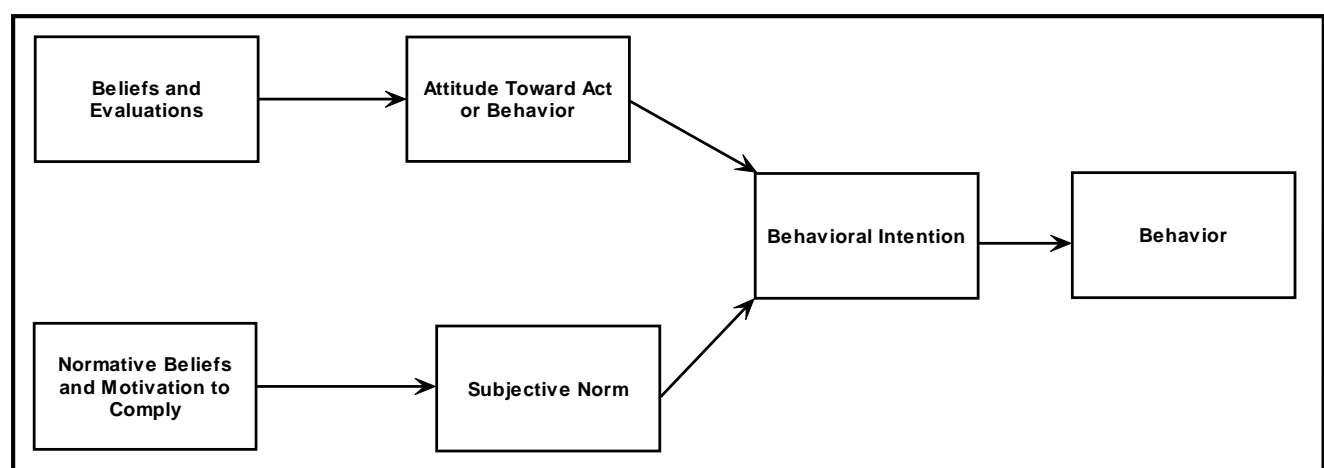

Figure 2. Theory of Reasoned Action (Ajzen and Fishbein, 1980)

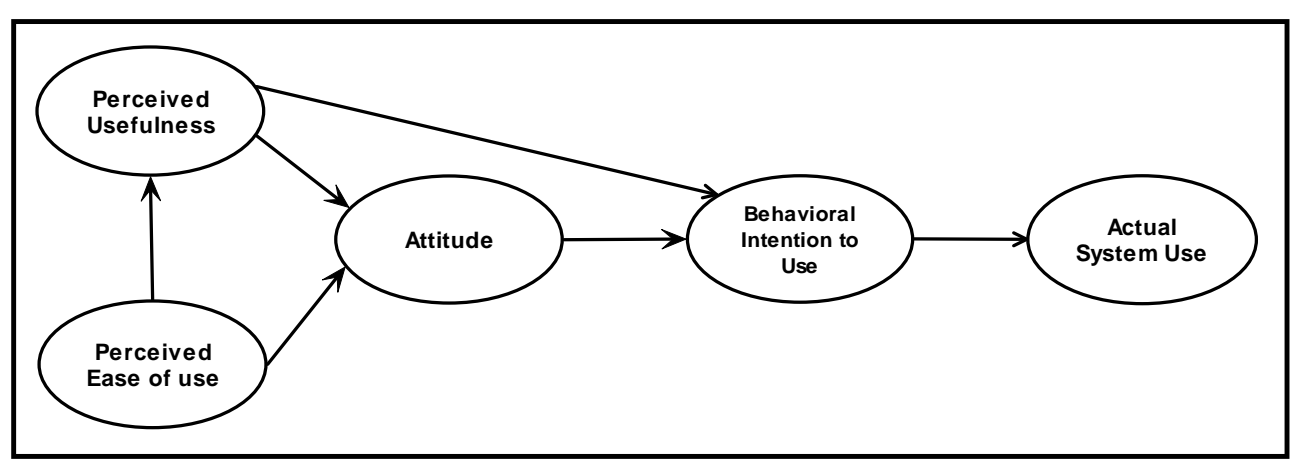

Figure 3. Original Technology Acceptance Model (Davis et al., 1989) 


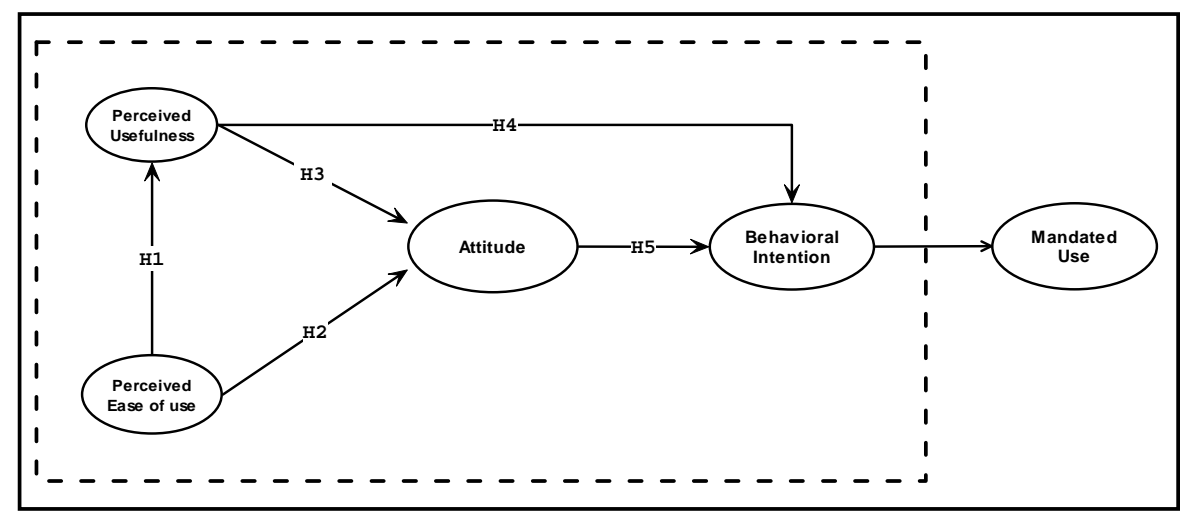

Figure 4. The research model

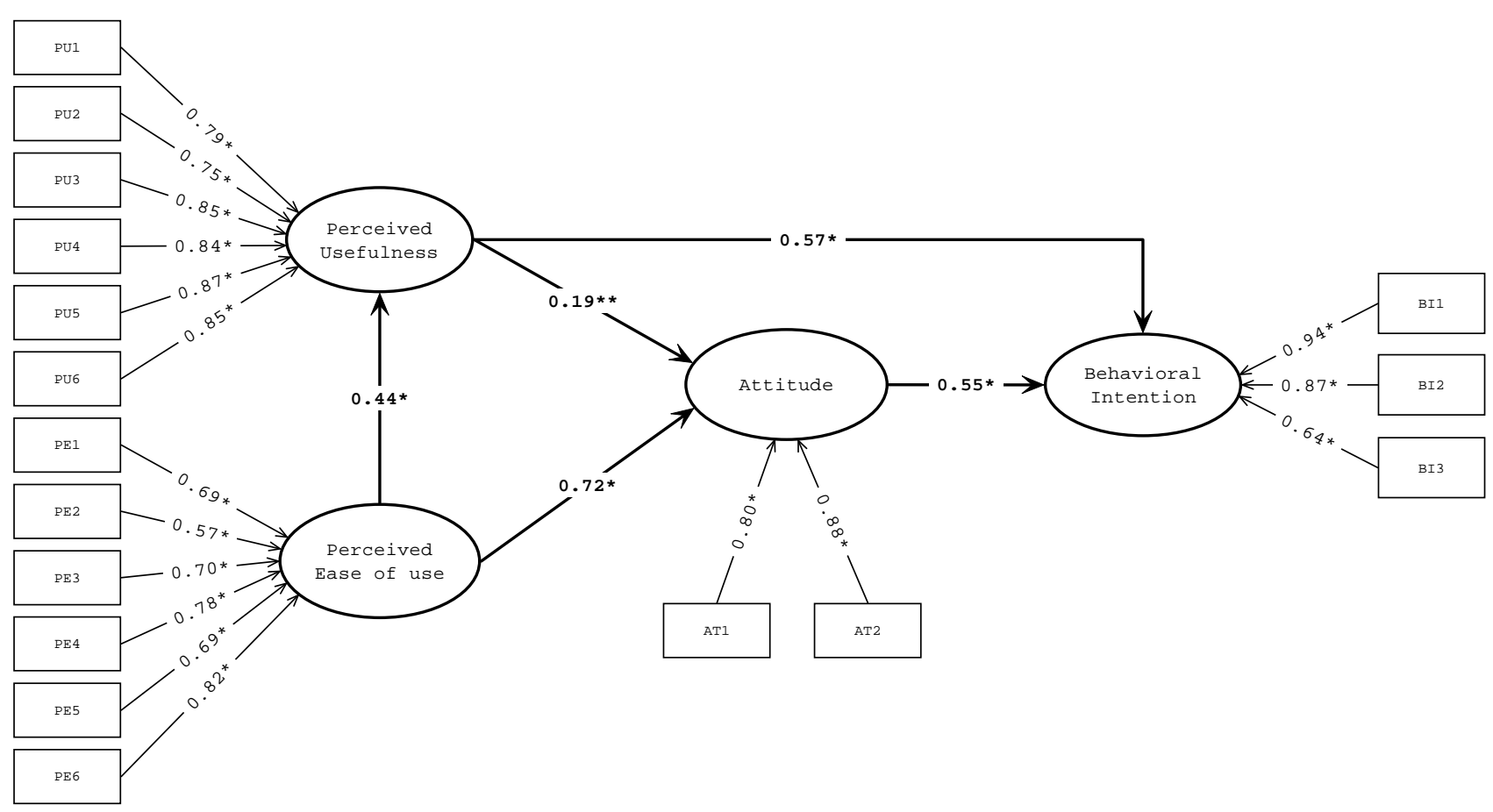

Figure 5. Model path coefficients

**P $<0.01 ; * \mathrm{P}<0.05$

Chi-Square $=172.89, \mathrm{df}=108, \mathrm{P}$-value $=0.00007, \mathrm{RMSEA}=0.057$ 